\title{
Desempenho da Revista Ciência \& Saúde Coletiva em 2020
}

Celebrando seus 25 anos de existência, a Ciência \& Saúde Coletiva (C\&SC, 2020), antes de tudo, aplaude sua equipe editorial, que, apesar dos transtornos causados pela pandemia, manteve a qualidade e a periodicidade da Revista. Foram 12 edições e dois suplementos especiais sobre a COVID-19. Todo o trabalho, realizado de forma remota, exigiu adaptações e criatividade para cumprir o compromisso de responder adequadamente à enorme demanda de divulgação científica da área de saúde. O ano de 2020 foi muito difícil, marcado por perdas, incertezas, aprendizados, mas também projetou um futuro de esperança e de confiança no desenvolvimento de vacinas, ainda que haja desafios de todas as ordens para o período pós-pandemia.

O objetivo deste editorial é apresentar aos leitores um balanço do trabalho da C\&SC no ano passado resumido em alguns números: 4.388 originais recebidos, sendo 339 aprovados (7,72\% do total); 3.634 textos recusados; 400 artigos publicados em português; 346 artigos traduzidos ou originalmente em inglês (86,5\% do total); 16 em espanhol. O material total divulgado (artigos originais, revisões, editoriais, resenhas e cartas) compôs um conjunto de 481 comunicações. E nesse acervo foi dado espaço especial aos textos sobre o novo coronavírus: 68 artigos ${ }^{1,2}$.

O perfil das edições foi marcado por estudos sobre doenças transmissíveis e agravos não transmissíveis em todo o ciclo de vida e segundo categorias socioculturais de classe, gênero, etnia/raça e idade ${ }^{3}$ (2020,25(8), e também apresentou análises das políticas e ações diversas, entre as quais destacam-se: edição comemorativa dos 40 anos de Alma-Ata (2020)4; acesso e qualidade dos serviços de saúde; atuação do setor nas desigualdades, vulnerabilidades e invisibilidades sociais; formação de trabalhadores da saúde; relação entre alimentação e saúde; envelhecimento e cuidados; e papel da informação e da comunicação em saúde. A última edição do ano ${ }^{5}$ foi dedicada à comemoração das bodas de prata da Revista, com uma revisão de sua contribuição para a saúde coletiva e para o SUS, mas também abordando as dificuldades, lacunas e perspectivas do periódico. $\mathrm{O}$ ano foi encerrado com chave de ouro em um webinário comemorativo apresentado ao vivo pelo YouTube no canal da Abrasco no dia 17 de dezembro de 2020 (confira em: https:// www.youtube.com/watch?v=0wH4TimPU-8).

Um balanço a respeito dos colaboradores: 1.936 autores brasileiros de todas as regiões do país e 155 estrangeiros publicaram na Revista. Desses últimos, por quantidade de contribuições, destacam-se os de Portugal, Colômbia, México, Espanha e Argentina. Em menores proporções, autores de Chile, Peru, Uruguai, Estados Unidos, Canadá, França, Itália, Alemanha, Reino Unido, Bélgica, Irlanda, Índia, Austrália, Malásia, Timor Leste, Haiti, Etiópia e África do Sul.

Quanto às métricas reconhecidas mundialmente, pelo quinto ano consecutivo a C\&SC ocupou o primeiro lugar em citações entre todas as revistas brasileiras de todas as áreas no Google Scholar (índice H5, 49; índice H5, mediana 67). Na base Scimago seu índice passou de 0,926 para 1,179. O índice FI/JCR relativo a 2020 aumentou para 1,336. Os passos lentos, porém firmes, da Revista são promissores, e o que mais importa é sua relevância para a população e a comunidade científica da área da saúde.

Maria Cecília de Souza Minayo (https://orcid.org/0000-0001-6187-9301) ${ }^{1}$

Romeu Gomes (https://orcid.org/0000-0003-3100-8091) ${ }^{2}$

Antônio Augusto Moura da Silva (https://orcid.org/0000-0003-4968-5138) ${ }^{3}$

${ }^{1}$ Escola Nacional de Saúde Pública Sergio Arouca, Fiocruz. Rio de Janeiro RJ Brasil.

${ }^{2}$ Instituto Fernandes Figueira, Fiocruz. Rio de Janeiro RJ Brasil.

${ }^{3}$ Departamento de Saúde Pública, Universidade Federal do Maranhão. São Luís MA Brasil.

\section{Referências}

1. Ciência \& Saúde Coletiva. O que a covid-19 revela e esconde. 2020; 25(Supl.1).

2. Ciência \& Saúde Coletiva. A pandemia que revirou o mundo. 2020; 25 (Supl.2).

3. Ciência \& Saúde Coletiva. Doenças infecciosas, agravos não transmissíveis e prevenção. 2020; 25(8).

4. Ciência \& Saúde Coletiva. Celebrando 40 anos de Alma-Ata nas Américas e Região Ibero-Americana. 2020; 25(4).

5. Ciência \& Saúde Coletiva. Ciência para a sociedade: 25 anos de história. 2020; 25(12). 